RESEARCH ETHICS

\title{
The standard of care debate: against the myth of an "international consensus opinion"
}

\author{
U Schüklenk
}

J Med Ethics 2004;30:194-197. doi: 10.1136/jme.2003.006981

It is argued by Lie et al in the current issue of the Journal of Medical Ethics that an international consensus opinion has formed on the issue of standards of care in clinical trials undertaken in developing countries. This opinion, so they argue, rejects the Declaration of Helsinki's traditional view on this matter. They propose furthermore that the Declaration of Helsinki has lost its moral authority in the controversy in research ethics. Although the latter conclusion is supported by this author, it will be demonstrated in this paper that there is not such a thing as an international consensus opinion, and that the authorities used by Lie et al as evidence in support of their claim should not be relied upon as authorities or final arbiters in this debate. Furthermore, it will be shown that arguments advanced substantively to show that lower standards of care are ethically acceptable in the developing world, conflate scientific with economic reasons, and ultimately fail to bolster the case they are designed to support.
Correspondence to: Professor U Schüklenk, Head, Division of Bioethics, Faculty of Health Sciences, University of the Witwatersrand,

Johannesburg, Wits 2050, South Africa;

udo@udo-schuklenk.org

Accepted for publication 10 December 2003

\section{INTRODUCTION: RECAP OF ARGUMENTS AND AREA OF AGREEMENT}

The cogent paper by Reidar Lie and colleagues advances two distinct types of arguments in support of their conclusion that we should accept less than the best current diagnostic and therapeutic method of care, as the control arm, in clinical research undertaken in developing countries. ${ }^{1}$ Their first argument is a procedural argument relying on the fact that some organisations in different countries and jurisdictions have reached this conclusion. Despite some concerns about the relevance of this fact (as exemplified in their correct statement that "moral questions are not decided simply by which view gets the most votes") the authors use this fact as evidence of an emerging international consensus (see, for instance, the heading of their article). Confusingly, also within their article, they concede that "it is also patently obvious that there presently is no worldwide consensus", which begs the question why they aim to give in their heading and for much of the article the impression that there is an international consensus opinion on this matter. Jonathan D Moreno is probably on the right track, when he states that "empirically, moral truth is in fact less likely to be achieved by groups, which are vulnerable to corruptions of political processes and interpersonal dynamics, than by well informed and reflective individuals". ${ }^{2}$ He also recognises, however, that although perhaps the epistemological critique of consensus finding activities is sound, from a pragmatic perspective, it is difficult to see how human institutions could work without some form of consensus. I shall return to this theme, albeit briefly, at the end of the next section. Although, as I will demonstrate, it is in fact the case that the consensus finding processes of the owners of most of the ethical guidelines mentioned by Lie et al were sufficiently flawed to disregard them, it is clearly necessary to identify an organisation that could legitimately direct an international consensus finding process. To my mind, and despite many misgivings about this institution, only the World Health Organization (WHO) is currently able to fulfil this role. More on that, however, in a moment.

The second argument advanced by Lie et al aims to demonstrate that the purported international consensus opinion is one that we should adopt, and it provides three distinct reasons for this conclusion.

I shall look at these two broad arguments in turn, before concluding that we should not accept the purported international consensus opinion either as a consensus opinion or as an ethically acceptable stance on this matter.

Let me highlight, however, where I strongly agree with the analysis provided by Lie et al. There has been some discussion internationally about the phrasing of the Declaration of Helsinki as opposed to the substance of the document. Even professionals finding themselves in agreement with the sentiments expressed in the declaration were not always happy with the wording. This certainly has come to a head with the so-called clarification the World Medical Association (WMA) adopted. In effect the declaration demands that the control group in any clinical trial should receive the best current proven diagnostic and therapeutic method of care unless there is a "compelling and scientifically sound methodological reason" not to do so. In other words, its traditional highest standard requirement is undermined by saying that any compelling scientific reason allows us to set it aside. This really would mean that an ethical question is decided exclusively by considerations of scientific methodology. As any philosophy undergraduate student knows, that is simply impossible. Lie et al are certainly correct in asserting that with this latest faux pas the WMA has lost any moral authority in the hotly 
contested standards of care debate. They are also correct in saying that we still have to deal with the document, because many people take the declaration as the final word on this matter. In fact, at the time of writing, in countries such as South Africa researchers are required by government regulation to abide by the declaration's provisions. That in itself is an odd thing, given that the South African government is not actually involved in, nor consulted on, the wording of the declaration, but that is perhaps a topic for another paper.

\section{PROCEDURE, PROCEDURE, PROCEDURE - THE FIRST ARGUMENT}

The first argument advanced by Lie et al is effectively that the traditional stance taken by the WMA on the standard of care issue has become the odd voice out, given that the Joint United Nations programme on HIV/AIDS (UNAIDS), the National Bioethics Advisory Commission (NBAC), the Council for Organisations of Medical Science (CIOMS), the European Group on Ethics in Science and New Technologies (EGE), and the UK-based Nuffield Council on Bioethics (NC) have come independently to the same different conclusion on the matter-namely that lower than best current standards of care are ethically acceptable, provided certain conditions are met. We have reason to be suspicious of claims that these organisations, institutions, and groups have reached these similar conclusions independently of each other, given that their various documents were published not at all independently of each other. Rather, these documents undoubtedly informed each other. Why would this matter? It matters, because neither of the organisations mentioned by Lie et al is actually anywhere near as large by way of representing real world membership as is the WMA. The obvious danger is that a few key individuals were chosen by whoever had the power in each of these smaller organisations to choose the members of the drafting committee. This would have allowed democratically unaccountable players to utilise their positions to manipulate outcomes. This is a serious concern about smallish groupings such as CIOMS, NBAC and NC, and their committee-based response to bioethical policy development. The underlying problems have been discussed and criticised in recent times in various contexts. ${ }^{3}$

Let me have only a brief look at some of the organisations and documents utilised by Lie et al to support this concern. They deploy the UNAIDS document on ethical issues in preventive vaccine research as a case in point. Lie et al claim as an example that "before the UNAIDS document was adopted, consultative meetings were carried out in Africa, Latin America, and Asia". To my knowledge these stakeholder-based consultations led to no international consensus at the time. For instance, the Latin American consultations led to a consensus document requiring the provision of antiretroviral therapy to infected trial participants as a condition sine qua non. This is not reflected in the actual UNAIDS guideline. The Latin American consultation's consensus document reads: "Preventive behaviour counselling, general HIV care and treatment, postexposure prophylaxis and antiretroviral therapy (whether early or late) were all considered to be subject to the same ethical imperative: that is, all should be provided to trial participants according to the best scientific evidence for effectiveness available at the time of the trial. There was a strong sense of consensus on this issue."**

The reason for this is that the UNAIDS leadership handpicked a small group of leading professionals to write guidelines as they saw fit. In South Africa, deliberations

*Professor D B Greco (Brazil) was the coordinator of this meeting; the quote is taken from a personal communication sent by Greco on 10 December 2003. among stakeholders and members of ethics committees rejected the UNAIDS document's notion that an HIV infection acquired during trial participation should never be seen as a trial related injury, and required instead that participants who become infected during the trials be provided with essential AIDS drugs. The notion that this would make the trials unaffordable and that one must consider more locally appropriate standards of care, which is one of the fundamental ideas of those favouring lower standards of care, was put up as a smokescreen by representatives of the South African AIDS Vaccine Initiative (SAAVI). This was combined with the threat that higher ("unaffordable") standards of care would make vaccine trials impossible and that this would mean the AIDS epidemic would never be curbed, etc. Only when the relevant ethics committees refused to budge, and in effect called the researchers' and their sponsors' bluff, did the sponsors and investigators come up, rather quickly, with an ingenious financing plan that now guarantees ethically appropriate standards of care, including antiretroviral therapy. To summarise: the UNAIDS document does not, in fact, represent an international consensus view on the matter at hand as for instance the discussions held and the decisions made in South Africa demonstrate. If anything, the document has been utilised unsuccessfully in South Africa (in a manner undoubtedly unintended by UNAIDS) to try to convince local ethics committees to accept lower levels of care (not including essential AIDS drugs) for those who become infected during trials. Both the standing of UNAIDS and the importance of this international guideline were wheeled out in an unsuccessful attempt to persuade ethics committees to relent in their demands for higher standards of care. $\dagger$

Similarly, CIOMS, despite its grandiose name, is a rather small organisation that was not even able to reimburse the travel expenses of developing world based delegates whom it had invited to attend a crucial meeting to discuss its draft research ethical guidelines. A few years ago I attended a major Asian bioethics gathering in Manila and asked whether anyone there was aware of the CIOMS consultation-a consultation that the organisation still claims was widely known. In fact, nobody in the audience except the person CIOMS had chosen for the meeting's authoring group knew anything about this matter. The CIOMS never responded to my request to inform interested members of the public how the comments received from the public were integrated into its final document; who had chosen the members of the drafting committee, and on what grounds, etc. Indeed, the CIOMS consultation was so secretive and non-transparent that, notwithstanding the high quality of much of the document, we would have little reason to give much weight to its contribution to the "international consensus". Its consultations failed the most basic test a policy document of this sort must pass-namely that of transparency. If, as Lie et al suggest, we should give more credence to the CIOMS guideline because of its capacity to provide reasons for its conclusions (as opposed to the Helsinki declaration, which relies entirely on the authority of the WMA), arguably little should then prevent us from giving the same credence to contributions from bioethicists in academic journals because frequently those are more concise than the arguments supporting the CIOMS conclusions. The idea that some documents should be given more credence than others, by virtue of the fact that they contain some sort

tl witnessed these attempts firsthand during a discussion held between leading members of the South African AIDS Vaccine Initiative and representatives of South African ethics committees in 2002, in Durban, South Africa. 
of supporting rationale, does not strike me as particularly convincing. After all, a guideline not providing the rationales for its conclusions could still very well be based on a more defensible ethical rationale than one that provides reasons, albeit bad ones. Still, Lie et al are correct when they implicitly demand that we should have justifications included in such guidelines. They help us to assess the ethical soundness of a particular guidance document.

It is perhaps important to recognise that CIOMS itself does not claim to represent an international consensus opinion, rather Lie et al suggest that the CIOMS agreement with other small groups' views on matters to do with research ethics leads to the emergence of an international consensus.

I could go on in this manner with regard to most of the organisations mentioned by Lie et al. The US NBAC under President Clinton's administration and its successor under President Bush's administration have long been the subject of criticism by professionals and the interested public, because, so it has been argued, some of their members were clearly political appointees. ${ }^{5}$ I do not wish to spend more space trying to support my claim that an international consensus among smallish operators with impressive names is not a sufficient reason to do away with the authority of the WMA, which represents more members of the medical profession in one single country, let alone across the world, than the rest of the organisations and institutions mentioned by Lie et al combined. As is often the case with smallish groups, they can easily be manipulated both during and even prior to the process of deciding who key drafting members are to be. The fact that those small operators handpick certain developing world-based participants to sit at their table, provides nothing by way of additional credibility. To my mind, it is also quite an indictment of these third worldbased frequent travellers in bioethics that they allow themselves to be used as evidence for a genuine participation of developing world stakeholders.

It is interesting, against this backdrop, that Lie et al note that the standards of care related questions were addressed "in the context of another trial for and by South African researchers". It is noteworthy that the crucial stakeholders, namely the participants (patients), were not offered a seat at the table, at least according to the description provided by Lie et al.

To summarise: the consultations referred to by Lie et al lack one or other of the crucial components required for them to be accepted as legitimate policy documents. A policy document of this sort should be based on a transparent method of working as far as the discussions (including selection of participants) and the utilisation of the input provided by professionals and the interested public are concerned. Also, seeing that in this particular instance the ramifications would be most severe for participants in developing countries, substantially greater efforts should be put into ensuring that the developing world-based delegates at consultative meetings are truly representative of their constituents. This would require that members of the same socioeconomic groups of patients affected by a given guideline be consulted in a meaningful way. Not all, but some ethical guidelines lack rational justifications for the substantive guidance provided. Justification of the policy guidance proposed should be mandatory for any document wanting to be taken seriously. We should certainly not accept views from the WMA or any other organisation as if they were somehow ex cathedra.

Arguably the best political/practical criterion for accepting an international policy document (as opposed to one we should accept on its ethical merit) is the truly representative nature of the organisation proposing it. Of those organisations currently in the guideline writing game, undoubtedly the WMA has by far the most legitimate claim to be taken seriously. It has worldwide, according to its own figures, eight million members of the medical profession. ${ }^{6}$ I agree with Lie et al, however, that, having seen its latest clarification, we have serious reason to question the WMA's competency to produce an authoritative document on this matter. Perhaps it is time for an international organisation such as the WHO to take it upon itself to issue such a policy document (also known as an "ethical guideline") and to be held accountable for it. The WHO, founded in 1948, is the United Nations' agency specialising in health related issues. In the organisation's own words: "WHO is governed by 192 member states through the World Health Assembly. The health assembly is composed of representatives from WHO's member states. The main tasks of the World Health Assembly are to approve the WHO programme and the budget for the following biennium and to decide major policy questions." ${ }^{17}$ Based on this, it seems clear that none of the other organisations currently engaged in the process of writing research ethical guidelines comes anywhere near the authority of the WHO. Only the WHO has good reason to claim to truly represent the international community. It should therefore begin a process of developing its own research ethical guidelines, based upon the criteria mentioned above.

What I should like to caution against in my conclusion, as far as the first argument by Lie et al is concerned, is the putting of any significant weight onto the fact that (in the absence of a WHO document on this matter) some small organisations come to conclusions different from those held by the WMA. The reference made by Lie et al to these small organisations seems to suggest that the legitimacy of the purported consensus lies in the fact that there is agreement, as opposed to legitimacy provided by way of reason or arguments. This, however, shows nothing by way of ethical argument and even if we accept Moreno's rationale, there are almost certainly good reasons to question, even on the procedural front, the standing of most of the documents cited by Lie et al.

\section{SUBSTANCE, SUBSTANCE, SUBSTANCE - THE SECOND ARGUMENT}

Reassuringly the contribution by Lie et al does not rely exclusively on the rhetorical ruse of an "international consensus" to sway us, but provides further rationales that are worthy of serious consideration.

\section{1) and 2) Valid science and social benefits to host community}

Lie et al argue that what they call the "international consensus opinion" requires a sound scientific reason for using lower standards of care. It seems to me that they (and the organisations they mention) conflate scientific and economic matters as far as the developing world is concerned. If it was the case that an empirical case could be made that only certain clinical trials in the developing world could, as CIOMS will have it, "yield scientifically reliable results that will be relevant to the health needs of the study population", ${ }^{8}$ I could go along with this argument. The reality, however, in all cases that I can think of (including the infamous perinatal HIV transmission prevention study that led to this debate") is that the only reason why "the established effective intervention cannot be used as a comparator" is economic as opposed to scientific. The rationale for the South African perinatal HIV transmission prevention trial, to my mind, has not been scientific but economic. Although it is true that the question was a scientific one, it is also true that the question was driven by economic issues as opposed to a scientific, medical necessity to investigate. Wanting to produce a cheaper drug regime because one cannot afford the standard treatment regime does not 
suggest any scientific necessity to conduct such a trial but an economic necessity. Similarly, wanting to develop a treatment regime that is easier to administer in a developing world context is not a scientific reason, it is an economic reason. I remain sceptical that the approach to such problems should lie in more research. Rather, it suggests that we should address the economic inequities that underlie much of the rhetoric, because it is these economic inequities that are making more likely the lower standards of care trials in developing countries. If we really want to "improve medical care for the world's poor", as Lie et al will have it, perhaps we should spend more time thinking about ensuring access to existing drugs as opposed to using this as a rationale for developing additional drugs. I have discussed this at length elsewhere, and provided a consequentialist ethical rationale for not permitting such research to go ahead..$^{11}$

\section{3) Favourable risk/benefit ratio}

This argument by Lie et al again relies heavily on an impoverished population to succeed. Of course, many trial participants in developing countries do not have access to basic health care. Their only recourse, frequently, is to participate in a trial. This is the primary reason why so many people in developing countries are so concerned about the issue of standards of care. Lie et al argue that "participants should not be denied any treatments with significant benefits that they would ordinarily receive". This idea would, even in the developed world, mean that different standards of care would be acceptable in trials undertaken in two-tiered healthcare systems. Those dependent on the public sector health service could be subjected to lower standards of care, whereas those with the resources to access the private sector could not be subjected to lower standards. One could even conceive of a trial where someone's standards of care would drop during the trial, because, during the trial, the person lost his or her job and therefore what he or she "would ordinarily receive" changed while the trial was under way. I should like to think that this is exploitative, because it does utilise the fact that trial participants have no reasonable alternative options as a justification for proposing a control that is also unreasonable. The justification of the unreasonable control is effectively that the participant without reasonable alternatives is not harmed by not being provided with a reasonable alternative while being in an unreasonable status quo. All this pretends that the situation of the participant is not changed by virtue of the fact that a usually well financed international sponsor comes into a developing country to conduct the research, and that no obligations toward the wellbeing of trial participants would flow from this. I do believe this is an argument difficult to sustain.

\section{CONCLUSION}

It may or may not be true that lower than the best current proven standards of clinical care in trials undertaken in developing countries are ethically acceptable. I should like to think, however, that I have shown that Lie et al have not demonstrated convincingly, either on the procedural or on the substantive front, that this, in fact, is the case. My concern is that the current guidance provided in the Declaration of Helsinki would lead to arbitrary conclusions, thanks to the incomprehensible clarification added recently. The WHO should take it upon itself to issue international research ethical guidelines, based on a consultative process meeting the criteria suggested in this article.

\section{ACKNOWLEDGEMENTS}

I should like to thank an anonymous reviewer for the Journal of Medical Ethics for triggering certain improvements, even though I fear that he or she might still not be fully satisfied with my responses to his or her comments.

\section{REFERENCES}

1 Lie R, Emanuel E, Grady C, et al. The standard of care debate: The Declaration of Helsinki versus the international consensus opinion. J Med Ethics 2003;30:190-193.

2 Moreno JD. Consensus by committee: philosophical and social aspects of ethics committees. In: Bayertz K, ed. The concept of moral consensus. Dordrecht: Kluwer, 1994:157.

3 Friele MB. Do committees ru(i)n the bio-political culture? On the democratic legitimacy of bioethics committees. Bioethics 2003;17:301-18.

4 Schüklenk U, Lott J. Bioethics and (public) policy advice. In: Thiele F, ed. Bioethics in a small world. Berlin: Springer, 2004, in press.

5 Minority Staff Special Investigations Division of the House Committee on Government Reform. Politics and science in the Bush administration. www.reform.house.gov/min (accessed 18 Aug 2003).

6 www.wma.net/e/members/list.htm (accessed 3 Dec 2003).

7 www.who.int/about/en/ (accessed 1 Nov 2003)

8 CIOMS. International ethical guidelines for biomedical research in developing countries. Geneva: CIOMS, 2002.

9 Lurie P, Wolf SM. Unethical trials of interventions to reduce perinatal transmission of the HIV in developing countries. N Engl J Med 1997;337:853-5.

10 Schüklenk U. Protecting the vulnerable: testing times for clinical research ethics. Soc Sci Med 2000;51:969-77.

11 Schüklenk U, Ashcroft RE. Affordable access to essential medication in developing countries - conflicts between ethical and economic imperatives. J Med Philos 2003;27:179-95. 